\title{
PORTUGUÊS E OUTRAS LÍNGUAS ROMÂNICAS: DESENVOLVIMENTO LINGUÍSTICO INTERSECCIONAL
}

\author{
PORTUGUESE AND OTHER ROMANIC LANGUAGES: \\ INTERSECTIONAL LANGUAGE DEVELOPMENT
}

\author{
Lorena Torres Timo ${ }^{1}$ \\ Dayana da Silva Gomes ${ }^{2}$ \\ Priscylla Fernandes dos Santos ${ }^{3}$
}

\section{Resumo}

Este artigo tem como objetivo apresentar estratégias de desenvolvimento linguístico de leitura e de escrita em consonância com os princípios do Método Eclético (LARSEN-FREEMAN, 2000) e da Abordagem Complexa (LARSEN-FREEMAN, 2016) ao considerar a homo e a heterogeneidade dos perfis de falantes de línguas românicas. Para tanto, propusemos a estudantes de uma instituição de ensino especializada em Português como Língua Adicional (PLA) atividades que considerassem a inteligibilidade existente entre línguas neolatinas. Os produtos pedagógicos gerados durante a pesquisa foram pautados nas competências receptivas que estas línguas podem incutir nos aprendizes. Conscientes da vantagem competitiva que possuem quanto à habilidade de compreensão e, consequentemente, quanto à habilidade de produção quando se considera as habilidades passivas e ativas de estudantes que dominam língua(s) de outras famílias linguísticas, aqueles que são proficientes em alguma língua latina percebem-se mais propensos e confiantes no aprendizado de outras línguas adicionais românicas.

\section{Palavras-Chave}

Ensino de Línguas Românicas. Intercompreensão linguística. Método interseccional. Atividades interseccionais.

\section{Abstract}

This paper aims to present reading and writing language development strategies in line with the principles of the Eclectic Method (LARSEN-FREEMAN, 2000) and the Complex Approach (LARSEN-FREEMAN, 2016) by considering the homo and heterogeneity of speakers of Romance languages' profiles. In order to do that, we proposed to students of an educational institution specialized in Portuguese as an Additional Language activities that considered the intelligibility existing between Neolatine languages. The pedagogical products generated during the research were based on the receptive competences that these languages can instill in the learners. Conscious of their competitive advantage over comprehension and, consequently, over production ability when considering passive and active abilities of students who know language(s) of other language families, those who are proficient in any Latin language perceive themselves more likely and confident to learn additional Romance languages.

\section{KeYWORDS}

Romance Language Teaching. Linguistic intercomprehension. Intersectional method. Intersectional activities.

\footnotetext{
1 Mestra em Estudos da Tradução pela Universidade de Brasília, professora do Instituto Cultural de Ensino de Português para Estrangeiros.

2 Licenciada em Letras, Português do Brasil como Segunda Língua pela Universidade de Brasília, professora Instituto Cultural de Ensino de Português para Estrangeiros.

3 Mestra em Estudos da Tradução pela Universidade de Brasília, professora do Instituto Cultural de Ensino de Português para Estrangeiros.
} 


\section{INTRODUÇÃo}

É incontestável o papel que o aprendizado de uma língua estrangeira tem na visão que o indivíduo forma do mundo. Neste sentido, quantos mais multilíngue o indivíduo, mais aberto a formas de estruturar o mundo ele é. Na busca pela ampliação das perspectivas do globo, existe um aumento no interesse em línguas menos estudadas, como o português. Stein-Smith (2018) indica que a intercompreensão das línguas românicas é um tema fortemente debatido dentro do contexto multilíngue devido ao seu alto grau de inteligibilidade com outras línguas românicas. O uso do Método Interseccional (MI) mostra-se, diante desse contexto, como um recurso editorial e professoral capaz de gerar resultados positivos em curto prazo.

No entanto, para haver eficácia no ensino de línguas baseado na intercompreensão, é preciso que haja materiais específicos que permitam usar a primeira língua (L1) do aprendiz como fator benéfico. Assim, os professores e os profissionais produtores de materiais didáticos - muitas vezes os próprios professores - devem estar preparados para trabalhar com o MI, sendo um conhecedor, ainda que não fluente, de outras línguas românicas e investindo na sua própria conscientização acerca da viabilidade do uso da intercompreensão entre línguas românicas como estratégia efetiva para o aprendizado de seus estudantes.

Considerando a familiaridade entre as línguas românicas, estratégias voltadas à inferência lexical mobilizando conhecimentos prévios do aluno são pertinentes para mostrar que, mesmo sem nunca ter estudado uma outra língua-alvo, o aluno já conhece uma ampla gama de vocabulário na nova língua que se propôs a aprender. O trabalho com materiais contrastivos ou bilíngues/trilíngues também pode facilitar a compreensão imediata do aluno e impulsionar o aprendizado dele, garantindo uma autoconfiança única e estimulando o aprendiz na busca do sucesso na proposta.

Para testar a validade de atividades que considerassem a intersecção de línguas românicas, foram elaboradas atividades didáticas que demandassem a habilidade de o estudante compreender o que lhe é familiar. Assim, após contextualização do português para falantes de línguas românicas e a relevância do MI e de levantamento das contribuições do Método Eclético (ME) para o desenvolvimento linguístico interseccional, apresenta-se proposta de atividade pedagógica interseccional e os resultados de sua aplicação em instituição educacional especializada no ensino de português como língua adicional (PLA).

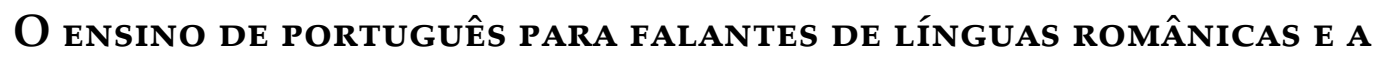 RELEVÂNCIA DO MÉTODO INTERSECCIONAL}

Após o fim da Segunda Guerra Mundial, e diante de todos os seus desdobramentos que deram às comunidades internacionais uma nova leitura das relações políticas, econômicas e institucionais, o fator linguístico assumiu um espontâneo papel de relevância para a sustentação desse novo sistema de integração entre os países. Como consequência, o conhecimento de novas línguas passou, então, a adquirir um valor de mercado, que agora se mostrava imprescindível para o crescimento e consolidação desse novo arranjo global. As línguas românicas - das quais se destacam o francês, o espanhol, o italiano, o português e o romeno - têm uma considerável significância nesse processo, uma vez que seu prestígio, refletido em termos culturais, históricos, políticos e eco- 
nômicos, faz com que sejam os principais expoentes na busca pela aquisição de uma nova língua (STEIN-SMITH, 2018).

Conforme evidenciado por Fernandes, foi sobre esse pano de fundo, por volta da década de 1980, que as discussões sobre a língua portuguesa se fortaleceram, tendo por objetivo a integração dos países lusófonos. Com agentes propulsores de variados cenários - líderes políticos, militares, intelectuais -, advindos, sobretudo, do eixo Brasil-Portugal, a lusofonia atinge o seu ponto mais notável no momento em que o país europeu busca sua inserção no cenário internacional pós-Guerra Fria, com vistas ao ingresso na Comunidade Europeia e à reaproximação de suas ex-colônias africanas. Somados a esses fatores determinantes para a ascensão da língua portuguesa, destacam-se a reconfiguração da economia mundial, as transformações no âmbito das relações internacionais e o entendimento da multiplicidade de culturas, que, juntos, conduziram à criação de organismos internacionais, a exemplo da Comunidade dos Países de Língua Portuguesa (CPLP), fundada em 1996.

Tendo em vista esse cenário de constantes transformações geopolíticas, econômicas e institucionais, a lusofonia passa a ascender expressivamente no cenário internacional, culminando na criação de organizações e associações especificamente focadas no ensino da língua portuguesa mundo afora, como, por exemplo, a Associação de Professores de Português (APP), criada em 1977, em Portugal, e a Sociedade Internacional de Português Língua Estrangeira (SIPLE), criada no Brasil em 1992. Desse período em diante, notou-se um crescimento considerável no interesse do português como língua adicional (PLA). Este termo, em linhas gerais, diz respeito a uma língua que o aluno aprende por acréscimo (LEFFA; IRALA, 2014), além da(s) que ele já conhece e que, por esse motivo, adota como ponto de partida a(s) língua(s) anteriormente adquirida(s). Essa perspectiva sugere uma convivência harmônica entre as línguas, considerando que o domínio de cada uma atende a objetivos diferentes e que não competem entre si, mas, antes, se complementam ${ }^{4}$.

Apesar desses esforços, dados encontrados em plataformas como o Ethnologue mostram que, entre os idiomas românicos anteriormente citados, o português não figura entre as primeiras línguas de interesse para uma língua adicional, assumindo, significativamente, uma posição terciária frente ao espanhol e o francês, por exemplo. Isso pode se justificar pelo espectro quantitativo - o espanhol é a segunda língua com mais falantes nativos no mundo e o francês é a segunda língua estrangeira mais procurada para aprendizado de língua adicional (STEIN-SMITH, 2018). Por outro lado, como também destaca Fernandes (no prelo), para entender os lugares ocupados pela lusofonia e adotar uma acepção mais contemporânea para o termo, é importante conhecer o espaço híbrido disputado pelas línguas na atualidade. Justifica-se isto pelos movimentos migratórios, os mercados e a evolução da informação e do conhecimento, que reforçam a ideia de se pensar no ensino de português sob uma ótica pluricêntrica. Ainda de acordo com dados compilados por Fernandes (no prelo), na atualidade, de acordo com o Instituto Camões (2016), 3,8\% da população mundial fala português, equivalendo a 261 milhões de pessoas. A língua é oficial nos nove Estados-membros da CPLP, em Macau e em 32 organizações internacionais, sendo, também, a quinta língua mais usada na internet, a terceira mais usada no Facebook e a quarta mais usada no mundo, atrás apenas do

4 Por essa razão, o termo PLA foi adotado para referir-se ao ensino de português ao longo deste artigo.

5 Ethnologue: Languages of the World é uma publicação anual de referência, impressa e on-line, que fornece estatísticas e outras informações sobre as línguas vivas do mundo. Foi publicado pela primeira vez em 1951 e agora é publicado anualmente pela SIL International, uma organização cristã sem fins lucrativos com sede nos EUA. O principal objetivo do SIL é estudar, desenvolver e documentar idiomas para promover a alfabetização e para fins religiosos. Cf: http://bit.ly/3afluCu. 
chinês, do espanhol e do inglês. Em vista disso e, uma vez feitas as considerações etimológicas do posicionamento das línguas românicas no cenário global, bem como, num enfoque mais específico, o da lusofonia, é válido lançar o olhar sobre as possibilidades de otimização do aprendizado do português para falantes de línguas românicas.

Stein-Smith (2018), em uma análise abrangente sobre a interrelação entre as línguas românicas, afirma que a história compartilhada e as similaridades atuais entre as línguas do tronco latino apontam para o uso efetivo do que ela denomina de "vantagem românica", com a finalidade de maximizar o aprendizado de idiomas românicos adicionais, seja por intercompreensão (compreensão de um idioma por sua semelhança com uma língua já conhecida pelo leitor ou ouvinte), seja através de métodos e materiais específicos de ensino, como estratégias de reconhecimento cognato. A principal vantagem do estudo de línguas estrangeiras dentro de um grupo de línguas estreitamente relacionadas é que, geralmente, o tempo e o esforço necessários para obter proficiência e fluência são significativamente menores do que o necessário para um iniciante sem o conhecimento prévio de uma língua românica. O desenvolvimento interseccional dessas línguas traz vantagens de cunho pessoal, cultural e profissional às suas populações, viabilizando, assim, as competências translinguísticas e transculturais do aprendiz.

Sendo assim, mostra-se pertinente a introdução de práticas pedagógicas que adotem o método interseccional, tendo como base o contato pregresso com alguma(s) língua(s) românica(s), considerando que essa metodologia assuma o papel de catalisar o processo de aprendizagem da língua portuguesa. Considerando a familiaridade entre as línguas românicas, estratégias voltadas à inferência lexical mobilizando conhecimentos prévios do aluno são interessantes para mostrar que, num primeiro contato, o aluno já conhece uma ampla gama de vocabulário na nova língua que ele se propôs a aprender. Em termos práticos, as estratégias para a construção da competência intercompreensiva poderiam advir da leitura de textos paralelos em línguas românicas distintas (LUNN; ALKHAS, 2017), no intuito de aumentar a confiança dos aprendizes. O trabalho com materiais contrastivos - textos informativos, reportagens, artigos e notícias - ou bilíngues/trilíngues também poderiam facilitar a compreensão imediata do aluno e impulsionar o seu aprendizado, garantindo uma autoconfiança única e estimulando o aprendiz na busca do sucesso na proposta.

Com o método interseccional, torna-se possível, também, promover o aperfeiçoamento das competências translinguística e transcultural (CARVALHO; LUNA FREIRE; DA SILVA, 2010) do aprendiz. Recorrer à bagagem cultural que o aluno traz da aquisição prévia ou do aprendizado prévio de uma língua latina apresenta um alto potencial de eficácia, uma vez que não apenas aspectos linguísticos, mas também aspectos culturais unem os povos que descendem da tão ramificada árvore latina. Além disso, o método proposto se tornaria um aliado para minimizar os possíveis desgastes na aquisição de uma nova língua adicional, reduzindo processos, tempo, e, como consequência, tornando-a muito mais atrativa.

\section{CONTRIbUições do MÉTOdo ECLÉTICO PARA O DESENVOLVIMENTO LINGUístico INTERSECCIONAL}

As práticas de desenvolvimento linguístico, aliadas às discussões teórico-científicas, especialmente no século XX, constituíram as bases das abordagens de ensino de línguas. Para traçar um breve percurso até a Abordagem Eclética, lembra-se que apenas do século XIX a prática de ensinar 
línguas foi reconhecida como profissão, especialmente, pela integração das línguas modernas no currículo escolar europeu diante da necessidade de diálogo entre os países daquele continente. A cientificidade do campo ganhou mais solidez com a proposta do Alfabeto Fonético Internacional, em 1886. Na prática pedagógica do ensino de línguas, a organização dos pressupostos teórico-científicos em categorias e subcategorias permitiu que as discussões da esfera científica alcançassem a sala de aula. Anthony (1963) propôs três níveis de organização: a abordagem, o método e a técnica. Em uma relação hierárquica, a abordagem constitui um conjunto teórico-prático, guia no processo de aprendizagem; o método equivale a um nível mais próximo à concretude entre a teoria e a prática, delimitando objetivos no processo de aprender; já a técnica, última parte da relação de hierarquia, consiste em recursos e estratégias para o desenvolvimento linguístico.

Quatro abordagens têm protagonismo nas pesquisas, práticas de ensino e mercado didático da atualidade: a estruturalista, a comunicativa, a sociointeracionista e a complexa, descritas no quadro abaixo com suas bases teórico-científicas e representações na práxis:

\begin{tabular}{|c|c|c|}
\hline $\begin{array}{l}\text { Abordagem } \\
\text { estruturalista }\end{array}$ & $\begin{array}{l}\text { Embasada no comportamentalismo cunhado } \\
\text { por Watson (1924) e concretizado nas práticas de } \\
\text { ensino pelas teorias de Skinner (1957), propõe a } \\
\text { aprendizagem pela formação de hábitos por meio de } \\
\text { estímulos, respostas e reforços. }\end{array}$ & $\begin{array}{l}\text { Perceptível, por exemplo, em } \\
\text { atividades de preenchimento de } \\
\text { lacunas para conjugação de verbos } \\
\text { e exercícios de repetição para a } \\
\text { prática dos sons da língua. }\end{array}$ \\
\hline $\begin{array}{l}\text { Abordagem } \\
\text { comunicativa }\end{array}$ & $\begin{array}{l}\text { Diante de uma reconfiguração do termo } \\
\text { competência, inicialmente proposto por Chomsky } \\
\text { (1957), Hymes (1972) delimita o conceito de } \\
\text { competência comunicativa. Apesar de não se basear } \\
\text { em uma teoria específica, a abordagem comunicativa } \\
\text { observa a importância da autonomia dos aprendizes, } \\
\text { oferecendo-lhes insumo e suporte para atuação em } \\
\text { contextos reais de comunicação. }\end{array}$ & $\begin{array}{l}\text { Presente nos diálogos que simulam } \\
\text { interações reais, nas adaptações de } \\
\text { textos autênticos para materiais } \\
\text { destinados a níveis específicos, } \\
\text { na contextualização de tópicos } \\
\text { lexicais e gramaticais em unidades } \\
\text { temáticas, dentre outros. }\end{array}$ \\
\hline $\begin{array}{l}\text { Abordagem socio- } \\
\text { interacionista }\end{array}$ & $\begin{array}{l}\text { Com auge a partir dos anos } 1990 \text { e também } \\
\text { chamada de interacionismo, têm forte influência dos } \\
\text { pensamentos de Piaget, Bakhtin e Vygotsky. Sob a } \\
\text { ótica sociointeracionista, a interação em contextos } \\
\text { socioculturais é fator fundamental para a construção } \\
\text { do conhecimento. Dessa forma, a aprendizagem } \\
\text { linguística parte sempre da esfera social para a } \\
\text { individual. }\end{array}$ & $\begin{array}{l}\text { Materializada pelo uso e produção } \\
\text { de textos autênticos, como e-mails, } \\
\text { propagandas, mensagens de texto, } \\
\text { entrevistas e podcasts para a } \\
\text { abordagem de tópicos linguísticos. } \\
\text { Posiciona-se diante da necessidade } \\
\text { de resolução de problemas de } \\
\text { cunho social, que requerem o } \\
\text { estímulo do pensamento crítico } \\
\text { dos aprendizes. }\end{array}$ \\
\hline $\begin{array}{l}\text { Abordagem } \\
\text { complexa }\end{array}$ & $\begin{array}{l}\text { Inicialmente debatida no ensino de línguas por } \\
\text { Larsen-Freeman (1997), considera o desenvolvimento } \\
\text { linguístico em si um sistema complexo, cujo } \\
\text { dinamismo é refletido por diversos fatores, como } \\
\text { a não linearidade de suas partes, ou subsistemas: } \\
\text { variantes individuais, contextos de aprendizagem, } \\
\text { influências de terceiros, dentre outros. }\end{array}$ & $\begin{array}{l}\text { Mais aplicável aos eixos } \\
\text { delimitadores de currículo, } \\
\text { syllabus e planejamento de } \\
\text { aula, está muito presente no } \\
\text { oferecimento de feedbacks que } \\
\text { promovam mudanças positivas } \\
\text { aos envolvidos no processo de } \\
\text { desenvolvimento linguístico. Além } \\
\text { disso, mostra-se na conscientização } \\
\text { do professor para a criação de } \\
\text { planos estratégicos diante da } \\
\text { imprevisibilidade e da diversidade } \\
\text { da sala de aula. }\end{array}$ \\
\hline
\end{tabular}

Quadro 1: Abordagens de desenvolvimento linguístico 
Diante da constante revolução no ensino de línguas, na atualidade, reflexo das Tecnologias de Comunicação e Informação (TICs) e da Comunicação Mediada por Computadores (CMC), utilizar abordagens outrora em alta, como a estruturalista, tornou-se um tabu. As reconfigurações no papel do professor, do aluno, do livro didático e de outras forças no processo de ensinar são, de fato, de suma importância no sucesso do desenvolvimento linguístico dos aprendizes na contemporaneidade. Mas até que ponto esse maniqueísmo no ensino de línguas (LEFFA, 1988) traz vantagens às práticas de ensino plurais?

Os movimentos migratórios da atualidade e as TICs, somados à diversidade dos contextos de aprendizagem, requerem uma atitude mais adaptativa nos contextos de desenvolvimento linguístico. Assim, a abordagem eclética, também debatida sob as terminologias de método eclético e ecletismo, surgiu da proposição de que cada abordagem de ensino, ou método, apresenta pontos fracos e fortes. Dessa forma, em consonância com a abordagem complexa, o ecletismo é uma solução para a dinamicidade do desenvolvimento linguístico, pois permite que o professor selecione práticas e estratégias benéficas a contextos diversos (BROWN, 2002). Aprender e ensinar com base no ecletismo traz mais sensibilidade aos envolvidos no processo, transforma o professor em um sujeito crítico-reflexivo diante da diversidade de bases teóricas, leva em consideração os históricos sociais e etnolinguísticos dos aprendizes, além de suas preferências de aprendizagem.

O professor guiado pelo ecletismo não molda sua prática a uma abordagem específica, mas, sim, às demandas dos aprendizes (WALI, 2009). Entretanto, para uma prática de sucesso, é fundamental que o professor saiba delimitar os objetivos de suas aulas. Apesar de a abordagem eclética não constituir um conjunto estrito, sendo flexível, o conhecimento teórico-cognitivo sobre as abordagens de ensino desempenha, junto à experiência, um papel significativo nessa delimitação, já que conflitos surgem deliberadamente nos contextos de aprendizagem, requerendo atitudes e decisões imediatas por parte do professor.

As características da abordagem eclética abrem portas para um dialogismo com a desenvolvimento linguístico interseccional entre línguas românicas, especialmente, na concretização de tarefas, como as propostas aos participantes deste trabalho. As atividades advêm de abordagens variadas e partem de um gênero autêntico escrito para promover (1) uma avaliação diagnóstica; (2) a ativação do conhecimento linguístico prévio do aprendiz e, finalmente, (3) tratar das diferenças entre as línguas já faladas por ele e o PLA. Essa proposta já é debatida nos estudos de Português para Falantes de Espanhol (PFE), em estudos como o de Carvalho (2002), que chama a atenção para a necessidade de uma postura mais positiva quanto ao conhecimento dos hispanofalantes ao aprenderem a língua, evitando a crítica constante de que falar espanhol é um obstáculo.

As técnicas usadas no desenvolvimento linguístico interseccional são multifacetadas e têm um cunho indutivo, conectado ao Foco na Forma (GRANNIER, 2014), abrangendo majoritariamente estratégias de depreensão, tradução, reescrita e criação textual. Dessa forma, apesar de haver técnicas mais estruturais e contrastivas no cerne da elaboração das atividades linguísticas interseccionais, essas não devem indicar uma barreira para se alcançar propósitos significativos no desenvolvimento do PLA, já que não se sugere a adoção exclusiva do método, mas, sim, seu uso como apoio, aliado a outros métodos e estratégias, como propõe a abordagem eclética. As tarefas interseccionais devem atuar como contextualizadoras para discussões autênticas na sala de aula, 
servir de insumo para a coleta de dados na realização de tarefas e gerar textos de aplicabilidade significativa a comunidades linguísticas específicas, como a acadêmica.

\section{CONCRETIZANDO O DESENVOLVIMENTO LINGUÍSTICO INTERSECCIONAL: ORGANIZAÇÃo E APLiCAÇÃo do MÉTOdo}

A proposta de desenvolvimento linguístico deste trabalho se dispõe a partir de uma investigação de base qualitativa e descritiva. Bortoni-Ricardo (2011) afirma que a pesquisa qualitativa procura entender, interpretar fenômenos sociais inseridos em contexto, assim, por meio dela, o pesquisador compreende como um processo ocorre em determinado ambiente, analisando como os atores sociais envolvidos nesse processo o percebem ou o interpretam. A análise dos dados também se baseou nos pressupostos da pesquisa descritiva, ao buscar explicações para os dados encontrados, observando-os e analisando-os (FLICK, 2013).

Dividimos o trabalho nas seguintes etapas:

1. Levantamento do perfil de aprendizes de português falantes de outras línguas românicas inscritos em cursos de língua portuguesa no Instituto Cultural de Ensino de Português para Estrangeiros (ICEPE), em Brasília-DF.

2. Oferecimento de propostas para a participação da pesquisa a esses aprendizes mediante a apresentação dos resultados esperados e o recolhimento de suas autorizações para participação com o Termo de Consentimento Livre e Esclarecido.

3. Mapeamento dos aprendizes-colaboradores por línguas românicas faladas, sendo essas L1 ou não, totalizando treze falantes de espanhol, quatro de francês e um de italiano.

4. Elaboração de atividades baseadas no MI e na Abordagem Eclética;

5. Realização de tarefas com os participantes;

6. Aplicação do questionário para que os participantes avaliassem suas experiências com as tarefas propostas.

As tarefas aplicadas aos participantes consistiram em traduções a partir de textos autênticos escritos em uma língua românica falada pelos aprendizes-colaboradores. Os textos apresentavam cunho político, econômico e cultural, majoritariamente de gênero jornalístico, para se trabalhar a intercompreensão com foco na habilidade de compreensão escrita. Nas atividades, destacamos as palavras idênticas na língua românica falada pelo aprendiz e na língua portuguesa, evidenciando também aquelas com certa similaridade e as distintas ortograficamente, como no exemplo abaixo: 
A) Leia o texto em italiano e traduza-o para o português. As palavras em negrito são as idênticas em italiano e em português, as palavras sem marcação têm certa similaridade e as palavras riseactas são totalmente diferentes.

Qual è la spiagga più bella del mondo? La classifica di Tripadvisor

http://www.today.it/speciale/prezzogiusto/news-lifestyle/quali-sono-le-spiagge-piu-belle-del-mondo-laclassifica-di-tripadvisor.html

La medaglia d'oro per la spiaggia più bella del mondo è assegnata alla Baia do Sancho sull'tsota di Fernando de Noronha, al largo delle coste del Brasile.

L'isola di Fernando de Noronha in particolare appartiene all'omonimo arcipelago situato a circa $350 \mathrm{~km}$ dalla costa del Brasile. Si tratta di un'oasi naturalistica protetta, diehrara patrimonio dell'Umanità dall'Unesco. La biodiversità, la ricchezza della flora e della fauna marine lo rendono uno dei tuoghi più scenografici al mondo per le immersioni.

La spiaggia di Baia do Sancho è accessibile solo via mare o percorrendo a piecti una spettacolare seala ferrata inserita in una spaceatura nella seogliera. Il prezioso ecossistema della spiaggia è preservato grazie all'accesso a numero chiuso.

B) Observe as recorrências e escreva as palavras abaixo em português:

\begin{tabular}{|l|l|l|l|}
\hline La medaglia d'oro & & lo rendono & \\
\hline per la & & luoghi più scenografici & \\
\hline spiaggia & & immersioni & \\
\hline Più & & solo & \\
\hline è assegnata & scala ferrata & \\
\hline sull'isola & & spaccatura & \\
\hline al largo delle coste & & scogliera & \\
\hline appartiene & & grazie & \\
\hline situato a circa & & chiuso & \\
\hline ricchezza & & & \\
\hline
\end{tabular}

C) Agora, diante do trabalho acima, traduza o texto do italiano para o português:

Quadro 2: Proposta de desenvolvimento linguístico baseado no MI

Selecionamos elaboradores com conhecimento avançado nas línguas românicas faladas pelos aprendizes-colaboradores, a saber, italiano, francês e espanhol, para a confecção dos materiais. Abaixo, um exemplo de tarefa baseada na língua francesa: 
A) Leia o texto em francês e traduza-o para o português. As palavras em negrito são as idênticas em francês e em português, as palavras sem marcação têm certa similaridade e as palavras riscadas são totalmente diferentes.

Femmes d'expatriés : quelles perspectives professionnelles? https://information.tv5monde.com/info/femmes-d-expatries-quelles-perspectives-professionnelles-280198

En France, entre 2 et 2,5 millions de personnes sont expatriées à l'étranger, seton tes cterniers chiffres publiés sur te site du Ministère de l'Europe et des Affaires étrangères. On dénombre autant de femmes que d'hommes mais nombreuses sont eelles à avoir suivi leur mari. Quelles sont leurs perspectives professionnelles dans te pays d'aceucit ? Une opportunité pour eertaines, un sacrifice pour d'autres. Selon une enquête réalisée en 2017 par Expat Communication, une agence française spécialisée tans l'accompagnement des expatriés, "“ans $92 \%$ des cas, t'est ta carrière de l'homme qui est à l'origine de ta mobilité et ta femme suit."

L'une des principales difficultés - pour tes femmes qui ont choisi de suivre leur mari à l'étranger - est de trouver une raison d'être en expatriation, de ne pas être là uniquement pour la famille. "Au début, se retrouver du jour

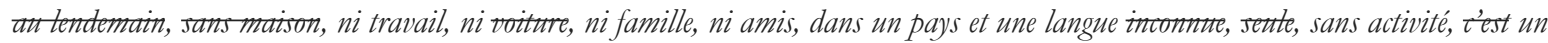

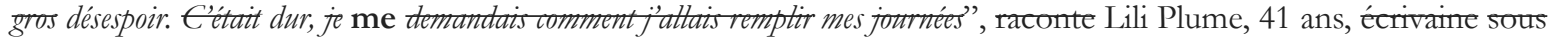
pseudonyme. Après avoir vécu trois ans au Brésil, eette ancienne enseignante française vit au Mexique depuis deux ans, à la suite de la mutation de son mari. Elle est l'auteure du blog Lili Plume Do Brasil et du tivre "Et si on partait vivre au Brésil ma chérie ?".

Đ’après l'étude d'Expat Communication, “49\% des sonjoints expatriés en rectherche d'emploi affirment s'être sacrifiés

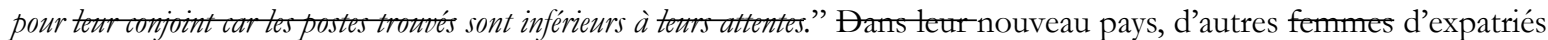
décident de tout recommencer à zéro en changeant de métier. "Je n'avais pas envie de travailler dans l'enseignement comme je te faisais en France. Au de six mois, je me suis lancée lans l'écriture, jai te temps et ça me plait. Mavie de femme d'expatrié

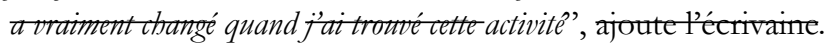

Malgré tes difficultés que peuvent reneontrer les femmes-d'expatriés dans leur nouveau pays, eette expérience peut être souree d'épanouissement. "Pour moi, l'expatriation été une grande chance et m'a ourt des portes sur d'autres perspectives professionnelles", téerit Lili Plume. Ee fait d'avoir du temps pour réfléchir à une nouvelle activité professionnelle est un réel atout. "On peut se lancer tans quelque chose tont on a rêvế", explique-t-elle également.

B) Observe as recorrências e escreva as palavras abaixo em português:

\begin{tabular}{|l|l|l|l|}
\hline personnes & & agence & \\
\hline sont & & française & \\
\hline expatriées & & spécialisée & \\
\hline étrangères & & carrière & \\
\hline nombreuses & & mobilité & \\
\hline Mari & & principales & \\
\hline perspectives & & difficultés & \\
\hline professionnelles & & réfléchir & \\
\hline pays & & uniquement & \\
\hline opportunité & & famille & \\
\hline sacrifice & & travail & \\
\hline enquête & & langue & \\
\hline réalisée & activité & \\
\hline en & & vivre & \\
\hline Ėtude & & nouveau & \\
\hline recommencer & & temps & \\
\hline quand & & difficultés & \\
\hline expérience & & portes & \\
\hline
\end{tabular}

C) Agora, diante do trabalho acima, traduza o texto do francês para o português: 
Após a realização das tarefas com os aprendizes-colaboradores, foi aplicado um formulário avaliativo sobre a atividade, do qual se destaca as seguintes questões:

1. Entre excelente, muito bom, bom, razoavelmente bom e ruim, como você classifica a atividade de intercompreensão?

2. Você acha produtiva a comparação entre o português e $<$ a língua em questão $>$ ? Explique.

3. Você gostaria de fazer mais atividades desse tipo? Se sim, que tipos de texto gostaria de produzir?

A classificação dos resultados da primeira pergunta evidenciou que, dos 18 aprendizes-colaboradores, $37 \%$ consideraram o uso do método excelente, 38\% muito bom, $12 \%$ bom, 13\% razoavelmente bom. Com os resultados da amostragem da questão dois, a aceitação foi unânime. 100\% dos aprendizes colaboradores consideraram a proposta didática produtiva.

Dentre as justificativas para a relevância do método, os aprendizes-colaboradores ${ }^{6}$ relataram: $^{-}$

AC14: "Esta atividade encoraja os alunos das línguas românicas a descobrir as semelhanças entre os idiomas, também as diferenças. As semelhanças podem apoiar o processo de aprender o português no meu caso".

AC9: "Será fácil de aprender outras línguas românicas depois de descobrir as semelhanças do português com estas línguas".

AC3: "A comparação entre as línguas é produtiva porque ajuda a entender diferenças numa maneira sistemática. Ajuda também a aprender bem os significados e os usos das palavras. Meu conhecimento em português aprofunda meu entendimento em outras línguas que eu conheço. Acho que ajudará aprender outra nova no futuro também”.

AC 5: "Aprender outras línguas é muito importante para ativar a mente, é estimulante, mas não gosto de fazer tradução".

AC 4: "A atividade é produtiva, acho sim, para identificar e corrigir os principais erros. Permite perceber que as duas línguas são muito semelhantes”.

Com base nos resultados, constatamos a aplicabilidade do método interseccional como relevante no desenvolvimento de PLA, visto que o aprendiz pode tirar vantagem das semelhanças entre as línguas. A amostragem indica uma boa recepção do método e das atividades propostas ao se considerar seu uso esporadicamente. Baseadas nas abordagens estruturalista e sociointeracionista, as propostas são utilizadoras do Foco na Forma (Grannier, 2014), da tradução, do preenchimento de lacunas e da leitura de textos autênticos, que devem servir de base para discussões de cunho crítico na sala de aula de PLA.

\section{RESUltados e REFLEXões}

Neste artigo, tivemos como objetivo abordar a relevância e debater sobre as vantagens de se utilizar o método eclético no ensino de português como língua adicional (PLA) para aprendizes falantes de outras línguas românicas, com foco no desenvolvimento linguístico interseccional.

Ressaltamos que o método eclético é abrangente e não se prende a uma única abordagem. Com ele, é esperado que o professor tenha a habilidade de perceber as demandas dos estudantes e que esteja preparado para solucioná-las utilizando a base teórica que julgar mais apropriada para cada situação. O professor, além de facilitador, torna-se um agente crítico e reflexivo, que não só

6 Utilizamos a abreviação AC, aprendiz-colaborador, seguida de um número relativo ao controle de preenchimento de questionários para manter o sigilo na identidade dos participantes. 
está preparado teoricamente, mas também leva em consideração o contexto histórico, social e linguístico de cada aprendiz e suas especificidades de aprendizagem. Dessa forma, é preciso que o professor seja sensível às necessidades de cada aprendiz, mas também, para que obtenha resultados reais e para que o aprendizado seja efetivo, é importante que saiba delimitar o conteúdo e os objetivos a serem alcançados em suas aulas.

Utilizamos o conceito de língua adicional trazido por Leffa (1998) em que o autor defende que a aprendizagem de uma nova língua se dá por acréscimo, ou seja, o aprendiz utiliza o conhecimento prévio de outra(s) língua(s) como ponto de partida para o aprendizado de uma nova língua. A língua adicional, no entanto, não deve concorrer com as línguas que o aprendiz já possui, já que ela tem um papel específico na vida do aluno, seja para trabalho ou lazer, por exemplo. O autor também descreve que o conceito de língua adicional traz consigo a valorização de algumas práticas em sala de aula, como o trabalho em equipe e a realidade social e linguística do aluno, bem como a ênfase no sistema linguístico, em que as atividades são baseadas em tarefas e projetos. Tendo isto em vista, os termos língua estrangeira e segunda língua se tornam limitantes para nossa pesquisa, já que nem sempre dão conta de todos os contextos que circundam a aquisição de uma língua.

Assim como Stein-Smith (2018), que traz o termo "vantagem românica" por conta da alta probabilidade de intercompreensão e inteligibilidade entre línguas românicas, defendemos, neste artigo, que a similaridade lexical entre línguas de mesmo tronco linguístico deve ser percebida e utilizada como um mecanismo facilitador no contexto de ensino/aprendizagem de uma língua adicional. Valer-se de elementos próximos entre os idiomas, valorizando-os como conhecimento prévio do aprendente, serve como um recurso pedagógico muito positivo e com resultados efetivos na aquisição do PLA.

Cabe considerar que, apesar das similaridades nos níveis linguísticos, especialmente na morfologia e na sintaxe, não se pode simplesmente fazer uma tradução ao pé da letra com o método interseccional. É importante que o professor-elaborador do material pautado no método interseccional seja um conhecedor ou estudioso da língua românica em contraste, visto que ele deverá se sensibilizar ao propor atividades desse tipo. Ressaltamos, entretanto, que o professor aplicador do material não precisa necessariamente ser fluente na língua românica falada pelo aprendiz.

Visando ao desenvolvimento linguístico interseccional entre as línguas românicas dos aprendizes de PLA, propusemos, nesta pesquisa, atividades textuais a partir de gêneros autênticos com o foco na forma, nas quais os alunos/participantes utilizaram de seu conhecimento prévio para resolver as questões apresentadas através de contraste e comparação entre dois sistemas linguísticos próximos, realizando tarefas de tradução, preenchimento de lacunas e reescrita dos textos. Os resultados mostraram que esse tipo de atividade é positiva e eficiente no que diz respeito à aquisição e aperfeiçoamento do PLA por parte dos aprendizes, principalmente pela ênfase nos detalhes da forma e estrutura das frases, mas que se adequa também como insumo para discussões em sala de aula. É importante destacar que esse tipo de atividade não deve nortear todo o ensino, mas deve ser utilizada como material de apoio dentre vários outros tipos de métodos e estratégias que contemplem a língua como ferramenta de prática social.

Por fim, concluímos que o conhecimento linguístico prévio precisa ser valorizado e que o aprendiz pode e deve tirar proveito das semelhanças entre as línguas. Esse conhecimento prévio di- 
recionado com a estratégia apropriada, é uma porta aberta para a aquisição de novos conhecimentos, novas conexões e maior compreensão da língua/cultura-alvo. Aos professores de língua cabe a mudança de paradigma em relação às críticas quanto ao uso de uma língua românica no aprendizado de outra. Também cabe ao professor compreender o uso dos materiais contrastivos, verificar sua aplicabilidade, e ter ao menos algum conhecimento de outras línguas românicas. Partindo dessa premissa, é importante que o professor evite coibições e tenha uma postura mais receptiva, destacando os pontos positivos e estimulando a confiança dos estudantes falantes de outras línguas românicas na aquisição da língua adicional.

\section{REFERÊNCIAS}

ANTHONY, E. M. Approach, Method, and Technique. In: ELT Journal, v. 17, n. 2, 1963, pp. 63-67.

BORTONI-RICARDO, S.M. O professor pesquisador - 2. reimp., 1. ed., São Paulo: Parábola Editorial, v. 1, 2011, pp. 31-40.

BROWN, H.D. English Language Teaching in the Post- Method' Era: Toward better Diagnosis, Treatment, and Assessment. In J. Richards and W. Renandya (eds.), Methodology in Language Teaching: An Anthology of Current Practice. Cambridge: Cambridge University Press, 2002, pp. 9-18.

CARVALHO, A. M. Português para falantes de espanhol: perspectivas de um campo de pesquisa.In: Hispania, n. 85, v. 3, 2002, pp. 597-608.

CARVAlHO, A. M., Luna Freire, J. e Da Silva, A. J. B. Teaching Portuguese to Spanish speakers: A case of trilingualism. In: Hispania, n. 93, v.1, 2010, pp.70-75.

CHOMSKY, N. Syntactic Structures. The Hague: Mouton, 1957.

EBERHARD, D. M., SIMONS, G. F., FENNIG, C.D.(eds.). Ethnologue: Languages of the World, c2019. Página inicial. Disponível em: http://bit.ly/2TkrVxO. Acesso em: 18/09/2019

FLICK, U. Introdução à metodologia científica: um guia para iniciantes. Tradução: Magda Lopes. Porto Alegre: Penso, 2013.

GRANNIER, D. M. Revisitando a proposta heterodoxa. Estudios portugueses y brasileños, v. 12, 2014, pp. 161-176.

HYMES, D. On Communicative Competence. In: J. B. Pride, John B.; Holmes, Janet (eds.). Sociolinguistics. Selected Readings. Harmondsworth: Penguin, 1972.

LARSEN-FREEMAN, D. Chaos/Complexity Science and Second Language Acquisition. Applied Linguistics, v. 18, n. 2, 1997, pp. 141-165. Oxford: Oxford University Press.

LARSEN-FREEMAN, D. Techniques and Principles in Language Teaching (2nd ed.). Oxford: Oxford University Press, 2000.

LARSEN-FREEMAN, D. Teacher Learning and Learner Learning in TESOL. TESOL Quarterly, n. 35, v. 4, 2001, pp. 608-629.

LARSEN-FREEMAN, D. Classroom-oriented research from a complex systems perspective. In: Studies in Second Language Learning and Teaching, v.6, n.3, pp. 377-393. Department of English Studies, Faculty of Pedagogy and Fine Arts, Adam Mickiewicz University, Kalisz, Polônia, 2016.

LARSEN-FREEMAN D. Looking abead: Future directions in, and future research into, second language acquisition. In: Foreign Language Annals, 2018, pp. 51-72.

LEFFA, V. J. Metodologia do ensino de línguas. In: Hilário Bohn; Paulino Vandresen. (Org.). Tópicos de lingǘstica aplicada ao ensino de línguas estrangeiras. 1ed. Florianópolis: UFSC, v. 1, 1988, pp. 211-236.

LEFFA, V., IRALA, V. B. O ensino de outra(s) língua(s) na contemporaneidade: questões conceituais e metodológicas. In: Vilson J. LEFFA; Valesca B. IRALA. (Orgs.). Uma espiadinha na sala de aula: ensinando línguas adicionais no Brasil. 1. ed., Pelotas: Educat, 2014, v. 1, pp. 21-48. 
LUNN, P. V.; ALKHAS, A. J. Learning French from Spanish and Spanish from French: A Short Guide. Washington, DC: Georgetown UP, 2017.

RESENDE, M. S. Notas sobre o ensino de Português como Língua Estrangeira. Domínios de Lingu@gem, v. 12, n. 2, jun. 2018, p. 871-891.

SKINNER, B.F. Verbal Behavior. Nova Iorque: Appleton-Century-Corfts, 1957.

STEIN-SMITH, K. The Romance Advantage - The Significance of the Romance Languages as a Pathway to Multilingualism. In: Theory and Practice in Language Studies, v. 8, n.10, 2018, pp. 1253-1260.

WALI, N.H. Eclecticism and Language Learning. In: Al-Fatih Journal, n. 39. Diyala University-College of Basic Education, 2009.

WATSON, J. Behaviorism. Nova Iorque, Norton, 1924. 